\title{
JUDICIALIZAÇÃO, RESERVA DO POSSÍVEL E COMPLIANCE NA ÁREA DA SAÚDE
}

\author{
JUDICIALIZATION, BUDGETARY AND FINANCIAL LIMITS OF \\ RESOURCES AND COMPLIANCE IN HEALTH SECTOR
}

\author{
Ingo Wolgang Sarlet \\ Giovani Agostini Saavedra
}

\section{Resumo}

A saúde tem, há muito, enfrentando vários desafios. Em especial, algumas distorções provocadas por excessos da assim chamada "judicialização" da saúde têm gerado muito debate. Se não é possível desconsiderar a relevância da atuação do Poder Judiciário, reflexo das patologias verificadas no próprio sistema público e privado de saúde, também é verdade que a intervenção judicial desmedida se revela preocupante. No presente artigo, pretende-se avaliar esse fenômeno a partir de dois aspectos: o da reserva do possível, como possível limitador do controle jurisdicional, e o do Compliance, como medida preventiva de distorções geradas por eventuais excessos dessa judicialização.

Palavras-chave: Judicialização. Saúde. Reserva do possível. Compliance.

\begin{abstract}
Health have faced various challenges. A special problem caused by excesses on the process so called "judicialization" of health raises lots of debate. If it's not possible to diminish the importance of Judiciary function, reflection of the pathologies found in health system itself, both public and private, it's also truth that the excesses in judiciary intervention in Brazilian Health Care System are very preoccupying. In this article, we intend to analyse this phenomenon in two aspects: the budgetary and financial limits of resources, as a material limit of the jurisdictional control, and Compliance, as a preventive measure of distortions generated by any excesses of the judicialization.
\end{abstract}

Keywords: Judicialization. Health. Budgetary and financial limits of resources. Compliance. 


\section{INTRODUÇÃo}

De há muito se sabe que a área da saúde no Brasil tem enfrentado uma série de desafios. Especialmente, após a deflagração de investigações e reportagens, que tornaram explícita a existência da chamada "Máfia das Próteses", várias iniciativas têm sido tomadas no poder executivo, no poder legislativo, bem como em órgãos de fiscalização como o CADE, para buscar conter e corrigir algumas distorções criadas pela assim chamada judicialização da saúde. Embora com isso não se esteja a desconsiderar a relevância da atuação do Poder Judiciário, provocado pelas funções essenciais à Justiça e pela cidadania, visto se tratar em grande medida de um reflexo das patologias verificadas no próprio sistema público e privado de saúde, também é verdade que em determinadas situações a intervenção judicial se revela preocupante sob diversos aspectos.

Nessa perspectiva, até mesmo pela inviabilidade de uma análise transversal e abrangente da problemática, destaca-se o impacto financeiro e orçamentário, traduzido pela conhecida noção de uma "reserva do possível", que tem sido recorrentemente esgrimida como limite fático (e jurídico) ao controle jurisdicional, também - e, considerando o número de processos - especialmente na área da saúde.

No presente artigo, pretende-se avaliar o fenômeno da assim chamada judicialização (doravante apenas judicialização) da saúde a partir de dois aspectos: o da reserva do possível, como possível limitador do controle jurisdicional, e o do Compliance, como medida preventiva de distorções, que podem surgem a partir de eventuais excessos dessa judicialização.

Para tanto, inicia-se pelo fenômeno da reserva do possível e suas dimensões para, na sequência, adentrar na seara do Complience, como meio de minimizar o impacto da intervenção judicial, mas, em especial, como modo de potencializar os recursos e racionalizar os gastos na seara da saúde, contribuindo para a própria sustentabilidade do sistema de saúde. 


\section{A ASSIM CHAMADA RESERVA DO POSSÍVEL, SUAS DIMENSÕES E SEU IMPACTO ${ }^{1}$}

Justamente pelo fato de os direitos sociais prestacionais terem por objeto - em regra - prestações do Estado diretamente vinculadas à destinação, distribuição (e redistribuição), bem como à criação de bens materiais, aponta-se, com propriedade, para sua dimensão economicamente relevante, ainda que se saiba, que todos os direitos fundamentais possuem uma dimensão positiva e, portanto, alguma relevância econômica (WIPFELDER, 1986). Tal constatação pode ser tida como essencialmente correta e não costuma ser questionada. Já os direitos de defesa - precipuamente dirigidos a uma conduta omissiva - podem, em princípio, ser considerados destituídos desta dimensão econômica, na medida em que o objeto de sua proteção como direitos subjetivos (vida, intimidade, liberdades etc.) pode ser assegurado juridicamente, independentemente das circunstâncias econômicas. ${ }^{2}$

É preciso que se deixe consignado, entretanto, que a referida "irrelevância econômica" dos direitos de defesa (negativos) deve ser compreendida de modo adequado, pois de há muito se sabe que todos os direitos fundamentais - na esteira da obra de Holmes e Sunstein e de acordo com a posição entre nós sustentada por autores como Gustavo Amaral (AMARAL, 2001) e Flávio Galdino (GALDINO, 2002) são, de certo modo, sempre direitos positivos, no sentido de que também os direitos de liberdade e os direitos de defesa em geral exigem - para a sua realização - um conjunto de medidas positivas por parte do poder público, que abrangem a alocação significativa de recursos materiais e humanos para a sua proteção e implementação. Assim, não há como negar que todos os direitos fundamentais podem implicar "um custo", de tal sorte que esta circunstância não poderia ser limitada aos direitos sociais de cunho prestacional (SGARBOSSA, 2010). Aliás, é preciso enfatizar, como o faz Nabais (2007), que não apenas todos os direitos fundamentais importam em custos, como tais custos podem ser compreendidos em sentido amplo, abrangendo custos ligados à própria existência e sobrevivência do Estado (vinculados, por exemplo, ao dever de defesa da pátria), quanto custos ligados ao funcionamento democrático dever de votar, como em 
sentido estrito, quando se referem - conforme, aliás, a perspectiva aqui privilegiada, os assim chamados custos financeiros públicos de todos os direitos.

Trilhando linha argumentativa similar, convergindo, portanto, com a posição aqui há muito enfatizada, no sentido de que existem diferenças entre os direitos civis e políticos e os direitos sociais, diferenças estas ligadas ao custo dos direitos, situa-se também o entendimento de Afonso da Silva (2008), para quem a realização dos direitos sociais "custa mais dinheiro", distinguindo entre "gastos institucionais", que seriam gastos comuns a todos os direitos (os gastos com a manutenção das instituições políticas e judiciais, por exemplo, que estão a serviço de todos os direitos) e os gastos diretamente referidos à realização dos direitos sociais, razão pela qual o autor entende que gastos gerais devem ser excluídos para efeito de comparação entre os direitos civis e políticos e direitos sociais, econômicos e culturais, designadamente, na sua esfera prestacional, convém acrescentar.

Vinculada a tal característica dos direitos fundamentais sociais a prestações está a problemática da efetiva disponibilidade do seu objeto, isto é, se o destinatário da norma se encontra em condições de dispor da prestação reclamada (isto é, de prestar o que a norma lhe impõe seja prestado), encontrando-se, portanto, na dependência da real existência dos meios para cumprir com sua obrigação. ${ }^{3}$ Já há tempo se averbou que o Estado dispõe apenas de limitada capacidade de dispor sobre o objeto das prestações reconhecidas pelas normas definidoras de direitos fundamentais sociais (BRUNNER, 1971), de tal sorte que a limitação dos recursos constitui, segundo alguns, em limite fático à efetivação desses direitos 4 .

Distinta da disponibilidade efetiva dos recursos, ou seja, da possibilidade material de disposição, situa-se a problemática ligada à possibilidade jurídica de disposição, já que o Estado (assim como o destinatário em geral) também deve ter a capacidade jurídica, em outras palavras, o poder de dispor, sem o qual de nada lhe adiantam os recursos existentes. ${ }^{5}$ Encontramo-nos, portanto, diante de duas facetas diversas, porém intimamente entrelaçadas, que caracterizam os direitos fundamentais sociais prestacionais. É justamente em virtude destes aspectos que se 
passou a sustentar a colocação dos direitos sociais a prestações sob o que se denominou de uma "reserva do possível", 6 que, compreendida em sentido amplo, abrange tanto a possibilidade, quanto o poder de disposição por parte do destinatário da norma.

Para além disso, colhe-se o ensejo de referir decisão da Corte Constitucional Federal da Alemanha, que, desde o paradigmático caso numerus clausus, versando sobre o direito de acesso ao ensino superior, firmou jurisprudência no sentido de que a prestação reclamada deve corresponder ao que o indivíduo pode razoavelmente exigir da sociedade, de tal sorte que, mesmo em dispondo o Estado dos recursos e tendo o poder de disposição, não se pode falar em uma obrigação de prestar algo que não se mantenha nos limites do razoável (STARCK, p. 303).

A partir do exposto, há como sustentar que a assim designada reserva do possível apresenta pelo menos uma dimensão tríplice, que abrange a) a efetiva disponibilidade fática dos recursos para a efetivação dos direitos fundamentais; b) a disponibilidade jurídica dos recursos materiais e humanos, que guarda íntima conexão com a distribuição das receitas e competências tributárias, orçamentárias, legislativas e administrativas, entre outras, e que, além disso, reclama equacionamento, notadamente no caso do Brasil, no contexto do nosso sistema constitucional federativo; c) já na perspectiva (também) do eventual titular de um direito a prestações sociais, a reserva do possível envolve o problema da proporcionalidade da prestação, em especial no tocante à sua exigibilidade e, nesta quadra, também da sua razoabilidade (SARLET, 2015).

Todos os aspectos referidos guardam vínculo estreito entre si e com outros ${ }^{7}$ princípios constitucionais, exigindo, além disso, um equacionamento sistemático e constitucionalmente adequado, para que, na perspectiva do princípio da máxima eficácia e efetividade dos direitos fundamentais, possam servir não como barreira intransponível, mas inclusive como ferramental para a garantia também dos direitos sociais de cunho prestacional. ${ }^{8}$

Por outro lado, justamente com base nas ponderações tecidas, não nos parece correta a afirmação de que a reserva do possível seja elemento integrante dos direitos fundamentais, ${ }^{9}$ como se fosse parte do seu núcleo essencial ou mesmo como se estive enquadrada no âmbito 
do que se convencionou denominar de limites imanentes dos direitos fundamentais. A reserva do possível constitui, em verdade (considerada toda a sua complexidade), espécie de limite jurídico e fático dos direitos fundamentais, mas também poderá atuar, em determinadas circunstâncias, como garantia dos direitos fundamentais, por exemplo, na hipótese de conflitos de direitos, quando se cuidar da invocação observados sempre os critérios da proporcionalidade e da garantia do mínimo existencial em relação a todos os direitos - da indisponibilidade de recursos com o intuito de salvaguardar o núcleo essencial de outro direito fundamental.

Cumpre anotar, aspecto que será igualmente retomado, que a noção de escassez (ou seja, a maior ou menor limitação dos recursos), em que pese essencialmente vinculada à dimensão fática da reserva do possível, como bem averba Olsen (2008), é uma noção artificial, resultado de construção humana, visto que não há como satisfazer simultaneamente em níveis ótimos todas as necessidades e desejos (visto que há necessidades criadas, inclusive mediante estímulo externo, como bem demonstram os estudos sobre a publicidade), razão pela qual, de acordo com a lição da autora, a reserva do possível há de ser compreendida como sendo uma espécie de condição da realidade, a exigir um mínimo de coerência entre a realidade e a ordenação normativa objeto da regulação jurídica.

Neste contexto, há quem sustente que, por estar em causa uma verdadeira opção quanto à afetação material dos recursos, também deve ser tomada uma decisão sobre a aplicação destes, que, por sua vez, depende da conjuntura socioeconômica global, partindo-se, neste sentido, da premissa de que a Constituição não oferece, ela mesma, os critérios para esta decisão, deixando-a ao encargo dos órgãos políticos (de modo especial ao legislador) competentes para a definição das linhas gerais das políticas na esfera socioeconômica (ANDRADE, 1987). É justamente por esta razão que a realização dos direitos sociais prestacionais - de acordo com a oportuna lição de Canotilho (1982) - costuma ser encarada como autêntico problema de competência constitucional: "ao legislador compete, dentro das reservas orçamentais, dos planos económicos e financeiros, das condições sociais e económicas do país, garantir as prestações integradoras dos direitos sociais, económicos e culturais". 
Por derradeiro, conquanto se possa partir da premissa de que em parte corretas as ponderações tecidas, reconhecendo-se as limitações representadas especialmente pela assim designada reserva do possível na esfera dos direitos fundamentais sociais de cunho prestacional, há que questionar até que ponto estes aspectos têm o condão de efetivamente impedir a plena eficácia e realização destes direitos, o que será aqui analisado na perspectiva do Compliance como ferramenta na esfera da prevenção e da otimização de recursos, de modo a evitar (ou minimizar) o recurso ao Poder Judiciário e, quando for o caso, o impacto de sua atuação.

\section{COMPLIANCE COMO PREVENÇÃO DE DISTORÇÕES E EXCESSOS DA JUDICIALIZAÇÃO DA SAÚDE ${ }^{10}$}

Não é exagero afirmar, que, em que pese Compliance exista no Brasil desde a década de noventa, somente nos últimos dois anos ele passou a chamar a atenção da vida acadêmica e do mundo empresarial de forma mais consistente. As razões desse interesse são conhecidas: de um lado, a Lei 12.683 de 09 de julho de 2012, que modificou a Lei de Lavagem de Dinheiro (Lei 9.613 de 03 de março de 1998), ampliou consideravelmente os setores obrigados a ter programas de Compliance, assim considerados como o conjunto de políticas, procedimentos e controles internos com vistas à prevenção à lavagem de dinheiro; (SAAVEDRA, 2012) ${ }^{11}$ além disso, a APn 470 (o caso do Mensalão) acabou também chamando a atenção de todos para o debate sobre a responsabilidade penal dos Compliance Officers (COSTA, 2014), bem como para o debate sobre a teoria do domínio do fato (LEITE, 2014). A Lei 12.846 de 01 de agosto de 2013 (também chamada de "Lei Anticorrupção", "Lei da Empresa Limpa”, "Lei da Probidade Administrativa” ou "Lei da Probidade Empresarial") completou esse ciclo. Ela veio, em grande medida, implantar, no Brasil, medidas que já eram conhecidas e aplicadas em países como os Estados Unidos da América. Inovação maior, na área de Compliance, foi a possibilidade de a existência de programas de Compliance ter um impacto positivo na aplicação das penalidades da lei, bem como a criação de hipótese de responsabilização objetiva da empresa no caso de atos de corrupção praticados em seu interesse ou benefício. Também 
essa lei acabou tendo sua importância ressaltada por um caso prático: a chamada "Operação Lava-Jato". Essa operação desencadeou uma onda de investigações nacionais e internacionais correlatas, em alguns casos fundamentadas em leis anticorrupção, o que contribuiu sobremaneira para o início de criação de uma consciência acerca da importância e do papel da nova lei.

Nesse contexto, vale ainda ressaltar, a excelente e oportuna iniciativa do Deputado Thiago Simon, que regulamenta, no Estado do Rio Grande do Sul, a Lei 12.846 de 01 de agosto de 2013, a Lei Anticorrupção. Essa lei tem vários méritos, mas o mais importante é tornar obrigatórios os avanços implementados pela Lei Anticorrupção, em âmbito federal, também no Rio Grande do Sul.

Mais recentemente, uma reportagem do Fantástico acabou desencadeando também a abertura de uma série de CPIs, dentre as quais destaca-se aquela realizada pela Câmara dos Deputados, pelo Senado e, com especial relevância, aquela promovida pela Assembleia Legislativa do Rio Grande do Sul e que têm chamado à atenção para um esquema de corrupção, no setor público e privado, no âmbito da saúde. Sem diminuir a importância dos fenômenos anteriormente descritos, não há a menor dúvida, que essas CPIs e essas distorções no mercado de saúde assumem um lugar de destaque, porque as fraudes ali descritas atingem diretamente os bens mais importantes do ser humano: sua integridade física, sua saúde e, em última instância, sua vida.

Esse fenômeno, porém, não é exclusivo do Brasil: na Europa e nos Estados Unidos houve escândalos de igual escala e o caminho encontrado para o enfrentamento desses problemas também se concentrou no Compliance. Essas medidas hoje estão concentradas no Código de Ética da Advamed (ADVAMED, 2009). No Brasil, um documento similar foi divulgado em 2015, trata-se do Ética Saúde - Acordo Setorial de Dispositivos Médicos. Este acordo consiste em um acordo setorial de Compliance para a área da Saúde e pretende concentrar e adaptar, para o Brasil, as melhores práticas e todas as medidas mais modernas de combate à corrupção no mercado de dispositivos médicos.

Essas e outras iniciativas mostram que o caminho adotado internacionalmente não se limita à repressão apenas, mas visa à prevenção. 
Especialmente porque, no mercado de saúde, o mais importante não é reprimir um fato que já causou um dano, mas garantir que o sistema como um todo funcione adequadamente. Pois bem, para que se realize esse desiderato é necessário institucionalizar medidas, que mudem sistemicamente o mercado como um todo e que não se limitem a punições pontuais de ações localizadas. 0 melhor meio para se atingir esse objetivo é, sem dúvida nenhuma, a criação de uma regulamentação de Compliance para a área da saúde no Brasil. O presente artigo pretende, portanto, abordar os principais avanços na área de Compliance buscando justificar as sugestões de projeto de lei, que sistematizam medidas de Compliance, que tem a vocação para corrigir as falhas do mercado de saúde.

\subsection{COMPLIANCE: DELIMITANDO O FENÔMENO}

Em grande medida, não seria errado afirmar que o surgimento do Compliance Criminal no Brasil é fruto de um processo complexo de expansão do Direito Penal. No Brasil, à primeira vista, parece não haver a menor dúvida dessa relação: o termo surgiu na década de noventa, década que, inegavelmente, marcou o início do processo de expansão do direito penal brasileiro (CAMPOS, 2010). Na verdade, o conceito de Compliance surgiu, no Brasil, na década de 90, mas, apenas nos últimos anos, ele também passou a ser objeto de estudos jurídicos. Formalmente, o conceito passou a ter relevância jurídico-penal, principalmente, com a entrada em vigor da Lei 9.613 de 03.03.1998 e da Resolução no 2.554 de 24.09.1998 do Conselho Monetário Nacional. Desde então, as instituições financeiras e, logo após, também as empresas do mercado de seguros em geral, passaram a ter o dever de, respectivamente, comunicar operações suspeitas, que pudessem implicar a prática do delito de lavagem de dinheiro (os chamados Deveres de Compliance) e de criar sistemas de controles internos, que previnam a prática de lavagem de dinheiro, que promovam o combate ao terrorismo, dentre outras condutas que possam colocar em risco a integridade do sistema financeiro.

Porém, o desenvolvimento do Compliance no Brasil não está apenas vinculado ao desenvolvimento de políticas de prevenção à lavagem de dinheiro e combate ao terrorismo, típicas do mercado financeiro, mas 
também ao surgimento da Governança Corporativa. De fato, no Brasil, Compliance, por muito tempo, foi compreendido, de um lado, como parte da implementação das "boas práticas" da "Corporate Governance". Neste caso, Compliance era entendido como um "mandamento ético" que deveria melhorar o relacionamento da empresa com os stakeholders e com o mercado ${ }^{12}$.

A palavra Compliance significa em tradução literal "estar em conformidade". Esta simples tradução, porém, esconde uma das maiores dificuldades da conceituação do termo: trata-se de um conceito relacional (ROTSCH, 2015), cujo significado só acaba por ser descoberto, portanto, através de uma análise do objeto com o qual se relaciona, dado que, por óbvio, quem está "em conformidade", está "em conformidade" com "algo". Compliance estabelece uma relação, portanto, entre um "estado de conformidade" e uma determinada "orientação de comportamento". Se esta "orientação de comportamento" é uma norma jurídica, está-se diante de Compliance jurídico, cuja designação varia conforme a área do direito, na qual a norma a ser seguida se insere. Essa reflexão, à primeira vista simples, procura explicitar alguns dos problemas de sua delimitação conceitual: é necessário definir o significado de (1) "estado de conformidade" e qual é a natureza normativa da (2) "orientação de comportamento", para que se possa, de forma minimamente plausível, iniciar uma reflexão sobre Compliance.

(ad 1) Já há algum tempo, pode-se encontrar, na literatura internacional, diversas e difundidas críticas à pura e simples definição de Compliance como estado de conformidade com as leis. Ora, a crítica é relativamente simples: se Compliance significa apenas estar em conformidade com as leis, o que há de novo? Não temos todos que estar em conformidade com as leis? Por que é necessária toda uma nova área do direito, toda uma nova teoria para tratar do óbvio: que temos de seguir leis? De fato, se Compliance fosse apenas isso, esta seria uma área do conhecimento fadada ao fracasso.

No nosso entendimento, "estado de conformidade" adquire, na área de Compliance, um completo e novo sentido: trata-se aqui de um estado "dinâmico" de conformidade, ou seja, o "estado de conformidade" significa aqui mais do que uma forma de estar no mundo, mas implica o 
"compromisso" com a criação de um sistema complexo de políticas, de controles internos e de procedimentos, que demonstrem que a empresa ou organização está buscando "garantir", que se mantenha em um estado de Compliance. Portanto, Compliance é a área do conhecimento, que busca definir qual é esse conjunto complexo de medidas que permite, face a um cenário futuro " $\mathrm{x}$ " de risco, garantir "hoje", com a máxima eficácia, um estado de conformidade de todos os colaboradores de uma determinada organização com uma determinada "orientação de comportamento".

(ad 2) Delimitar a "orientação de comportamento" é a segunda das dificuldades típicas do Compliance. Essa dificuldade está diretamente ligada àquela de definição da natureza jurídicas das normas a serem seguidas, afinal, o Compliance refere-se somente a "normas jurídicas"? Se se responde afirmativamente a essa pergunta, a primeira objeção que se poderia apresentar seria: "qual é, então, a natureza jurídica de um Código de Ética ou de um Código de Conduta? Tratam-se aqui de normas jurídicas?" A princípio não e, mesmo assim, nenhum estudioso ou especialista da área diria que Compliance não implica seguir essas normas de comportamento. Nesse sentido, um dos problemas do Compliance é que ele lida com fenômenos diversos de autorregulação, desde a autorregulação tradicional à chamada "autorregulação regulada". Tratam-se de normas de orientação de comportamento, que não têm natureza jurídica, mas que passam a ter "relevância jurídica" ou por força de contrato (através das conhecidas "cláusulas contratuais de Compliance") ou por força de lei (como, por exemplo, a Lei Anticorrupção que atribuem explicitamente consequências jurídicas para aquelas empresas que tiverem Códigos de Ética e Códigos de Conduta, ou seja, deixa claro que a existência dessas normas internas passa a ter impacto na forma como será aplicada a pena no caso concreto).

Portanto, Compliance consiste em um estado dinâmico de conformidade a uma orientação normativa de comportamento com relevância jurídica por força de contrato ou lei, que é caracterizado pelo compromisso com a criação de um sistema complexo de políticas, de controles internos e de procedimentos, que demonstrem que a empresa está buscando "garantir", que se mantenha em um estado de Compliance.

Portanto, a primeira característica atribuída ao termo Compliance é a prevenção. Diferentemente do Direito Penal ou Administrativo sancio- 
nador tradicionais, que trabalham na análise ex post de ilícitos, ou seja, apenas na análise de condutas comissivas ou omissivas que já violaram, de forma direta ou indireta, algum bem jurídico digno de tutela do Estado, o Compliance trata o mesmo fenômeno a partir de uma análise ex ante, ou seja, de uma análise dos controles internos e das medidas que podem prevenir a persecução penal da empresa ou instituição financeira. Exatamente por isso, o objetivo do Compliance tem sido descrito como a "diminuição ou prevenção de riscos compliance" (COIMBRA, 2010). Segundo posição dominante, portanto, as empresas e organizações deveriam criar os chamados Compliance Officers que teriam a responsabilidade de avaliar os riscos compliance e criar controles internos com o objetivo de evitar ou diminuir os riscos de sua responsabilização penal.

Por outro lado, os Compliance Officers têm sido criados também com o objetivo de investigar "potenciais criminosos" no âmbito de atuação da empresa. No âmbito do debate internacional, muito se tem discutido acerca dos deveres de comunicação de fatos potencialmente criminosos às autoridades competentes pelos Compliance Officers e de sua responsabilização penal. Recentemente, na Alemanha, por exemplo, o BGH (Bundesgerichthof) condenou um Compliance Officer por entender que este, ao assumir a responsabilidade pela prevenção de crimes no interior da empresa, assume também uma posição de garante e, portanto, deve ser punido criminalmente por ter assumido a responsabilidade de impedir o resultado, por ter obrigação de cuidado, proteção e vigilância e, no caso concreto, não ter criado um programa de Compliance capaz de cumprido esse dever, dado que, no caso concreto, esse programa não se mostrou eficaz e permitiu que a empresa fosse utilizada para a prática de crimes ${ }^{13}$.

Como se pode ver, o desenvolvimento do Compliance parece implicar um paradoxo ${ }^{14}$. 0 objetivo do Compliance é claro: a partir de uma série de controles internos se pretende prevenir a responsabilização penal. A sua concretização, porém, ao invés de diminuir as chances de responsabilização penal, cria as condições para que, dentro da empresa ou instituição financeira, identifique-se uma cadeia de responsabilização penal, pois a forma como os Compliance Officers têm sido constituídos acaba por coloca-los na posição de garante. Com isso, as chances de responsabilização penal aumentam ou invés de diminuir, ou seja, a criação 
de Compliance Officers, que deveria zelar pela diminuição de riscos compliance acaba, paradoxalmente, por aumentá-los, principalmente, porque os Compliance Officers, por sua vez, segundo doutrina majoritária, devem ser supervisionados diretamente pelo Conselho de Administração (ou órgão similar de gerência da empresa) fato que, obviamente, coloca em risco de persecução penal toda a administração da empresa.

Como já introduzimos acima, o termo Compliance tem origem na língua inglesa e é uma derivação do verbo inglês to comply, que significa estar em conformidade, cumprir, executar, satisfazer, realizar algo imposto. No âmbito empresarial e, principalmente, das instituições financeiras, o termo tem sido conceituado da seguinte forma: "Compliance é o ato de cumprir, de estar em conformidade e executar regulamentos internos e externos, impostos às atividades da instituição, buscando mitigar o risco atrelado à reputação e ao regulatório/legal" (COIMBRA/MANZI, 2010, p. 2).

A partir desse conceito, pode-se apreender um problema que precisa ser enfrentado por todo aquele que quiser tratar seriamente do tema: a abrangência do fenômeno. Entendido dessa forma, o termo Compliance abarcaria quase todo o tipo de regulações, ou seja, os Compliance Officers teriam, como obrigação, avaliar constantemente os procedimentos da empresa com vistas a garantir que ela estivesse em conformidade com todas as exigências legais, nacionais ou internacionais, que, de forma direta ou indireta, tivessem influência ou fossem aplicáveis à sua atividade, sejam elas trabalhistas, previdenciárias, ambientais, penais etc. De fato, nos EUA e nos países da Europa ocidental, especialmente na Alemanha, os Compliance Officers têm essa função abrangente. Nesses países, não são apenas instituições financeiras que têm os chamados "deveres de Compliance" (BARBOSA, 2010, p. 489-510), mas todas as empresas, sejam elas sociedades anônimas, empresas de grande porte ou mesmo pequenas e médias empresas ${ }^{15}$.

Nesse sentido, os Compliance Officers funcionam, portanto, como um guardião da empresa que teria, por principal função, garantir que a empresa permanecesse dentro dos limites da legalidade. Porém, se esse é o significado do termo Compliance, surge um segundo problema: o caráter "quase-tautológico" do termo, dado que simplesmente afirmar que a empresa tem de se adequar às leis é uma trivialidade. Afinal, não só as 
empresas, mas todos os cidadãos de um país devem respeitar as leis e agir dentro de seus limites. Portanto, se há alguma novidade no fenômeno do Compliance, ela não pode ser buscada nesse seu aspecto. Na verdade, parece que a originalidade do fenômeno somente pode ser captada se o procuramos analisar do ponto de vista do direito penal e da criminologia.

A primeira pergunta relevante para quem analisa os deveres de Compliance é: qual seria a consequência do descumprimento dos deveres de Compliance? Na prática das varas federais e na doutrina, encontram-se três correntes. A primeira entende que se deve recorrer aos artigos da Lei 7.492/86 para coibir o descumprimento dos deveres de colaboração, especialmente, aos arts. 16 e 22 e, eventualmente, ao art. 4․ Contra essa posição, argumenta-se que as Leis 7.492/86 e 9.613/98 regulam fenômenos diferentes, sendo que só a segunda trata dos deveres de Compliance. Portanto, os deveres de Compliance não se destinariam à tutela do sistema financeiro, mas, somente, à identificação de movimentações financeiras que indicariam a possibilidade de se estar diante do crime de lavagem de capitais. Nesse caso, portanto, seria necessária a criação de um tipo específico, que ainda não foi criado, nem mesmo pela nova lei de lavagem ${ }^{16}$.

Uma segunda corrente defende que a responsabilidade pela inobservância das obrigações de Compliance seria meramente administrativa, nos termos dos arts. 12 e 13 da Lei 9.613/98, sendo punível com sanções de advertência ou multa pelo órgão regulador da respectiva instituição ou, em sua ausência, pelo COAF ${ }^{17}$ A nova lei de lavagem reforçou esse entendimento, pois deixou claro que se aplica multa às pessoas referidas no art. 9으.

Por fim, sinaliza-se para o risco de, em breve, o descumprimento dos deveres de Compliance serem associados à posição de garante (SAAVEDRA, 2011). Um primeiro sinal nesse sentido foi dado pelo Tribunal Regional Federal da 4⿳a ${ }^{a}$ Região: “(...) Desse modo, é forçoso reconhecer que as operações marginais de mero ingresso de valores no país por parte dos clientes das instituições financeiras são atípicas, remanescendo apenas a possibilidade de eventual prática de sonegação fiscal, que, como é cediço, pressupõe a constituição definitiva do crédito tributário, o que não é o caso, ou ainda a punição dos gestores da instituição financeira clandestina pelo delito do artigo 16 e pelo crime de lavagem de dinheiro 
por violação dos deveres de compliance, quando perpetrado no âmbito da instituição financeira autorizada" (BRASIL, 2010) ${ }^{18}$.

Recentemente, em função da Ação Penal 470 (Mensalão), a utilização da forma omissiva imprópria para responsabilização dos Compliance Officers parece estar se consolidando na jurisprudência. Porém, ao contrário do que se seria esperado, ainda não se logrou êxito em definir adequadamente os critérios materiais dessa forma de responsabilização criminal $^{19}$.

\subsection{COMPLIANCE NA ÁREA DE SAÚDE}

Normalmente, na literatura especializada, os requisitos básicos do programa de Compliance são considerados os seguintes (COIMBRA, 2010, p. 37 e ss.):

1. Normas, regras e padrões de ética, de conduta e política e procedimentos escritos;

2. Designação de um Diretor de Compliance e criação de um Comitê de Compliance;

3. Educação e treinamento para fornecer conhecimento de forma efetiva;

4. Canal de comunicação anônima de eventuais problemas de Compliance;

5. Monitoramento proativo de processos específicos e documentados para fins de Compliance e ajuda na redução de problemas identificados;

6. Comunicação efetiva e ações disciplinares e corretivas.

Ainda, para ser considerado efetivo, um programa de Compliance precisa ser implementado obedecendo às seguintes fases:

1. Avaliação de risco (risk assessment);

2. Elaboração de projeto de implementação, que seja adequado ao tamanho, à cultura e às especificidades da empresa e que seja estruturado com base nos parâmetros desenvolvidos na avaliação de risco; e

3. Implementação do projeto.

Na área da saúde, porém, o foco do Compliance está na promoção de interações éticas entre Empresas e os indivíduos ou entidades que estão envolvidos na provisão de serviços de saúde aos pacientes e que compram, alugam, recomendam, usam ou encaminham a compra ou 
aluguel de Tecnologias Médicas das Empresas, ou seja, dos chamados Profissionais da Saúde (ADVAMED, 2009, p. 1-2). Isso porque:

[...] o desenvolvimento das Tecnologias Médicas depende muitas vezes de alto grau de interação directa com os Profissionais de Saúde - ao contrário dos medicamentos, que agem no corpo humano por meios farmacológicos, imunológicos e metabólicos. Por exemplo, as Tecnologias Médicas implantáveis muitas vezes são aplicadas no corpo humano para repor ou fortalecer uma parte corporal. As Tecnologias Médicas Cirúrgicas muitas vezes servem como extensões das mãos do médico. Em outras circunstâncias, as Tecnologias Médicas são reagentes não invasivos, instrumentação e/ou software que auxiliam as decisões de diagnóstico, monitorização e tratamento feitas pelos Profissionais de Saúde. Algumas Tecnologias Médicas trabalham em sinergia com outras tecnologias, ou são acopladas com outros produtos que empregam dispositivos da maneira mais segura e eficaz. Muitas Tecnologias Médicas exigem apoio técnico durante e após o seu uso (ADVAMED, 2009, p. 1-2).

Em função disso, o Compliance, na área da saúde, além dos elementos acima, deve contemplar ainda os seguintes mais específicos (ÉTICA SAÚDE, 2014):

- Comprometimento da liderança gerencial sênior e uma política anticorrupção claramente articulada e que aborde não só as interações com o poder público, mas também as interações com profissionais da saúde;

- Implementação de políticas e procedimentos por escrito, os quais visam a dar publicidade e transparência às relações estabelecidas entre empresas e profissionais da saúde;

- Políticas, procedimentos e controles internos formalizados, escritos e manualizados, que visem a garantir a interação ética e legítima da empresa com profissionais da saúde no caso de celebração de contratos de consultoria ou de prestação de serviços;

- Políticas, procedimentos e controles internos formalizados, escritos e manualizados, que disciplinem despesas e a concessão de patrocínios, especialmente quando estes envolverem profissionais da saúde;

- Políticas, procedimentos e controles internos formalizados, escritos e manualizados, que garantam a não concessão de incentivos a profissionais da saúde e que, portanto, estabeleçam internamente a proibição do patrocínio de entretenimento e recreação a esses profissionais e seus familiares;

- Políticas, procedimentos e controles internos formalizados, escritos e manualizados, que garantam uma interação ética e em conformidade 
com a legalidade de empresas com profissionais da saúde, no que diz respeito a almoços de negócios, concessão de brindes e presentes, itens de demonstração e doações para instituições, organizações, institutos ou hospitais;

- Designação de um oficial de Compliance e/ou um comitê de Compliance, com supervisão, autonomia e recursos necessários; responsáveis por analisar e fazer cumprir as provisões prescritas;

- Realização de treinamentos e educação eficazes de funcionários e profissionais vinculados à empresa;

- Desenvolvimento de linhas eficazes de comunicação (incluindo uma opção para realizar relatos anônimos);

- Realização de avaliações de riscos, monitoramento e auditoria internas;

- Padrões de execução do programa, através de normas disciplinares amplamente divulgadas;

- Ação rápida quando problemas forem detectados e a realização de ações corretivas e/ou sanções disciplinares;

- Realização de devida diligência (due diligence) em suas relações com terceiros.

- Educação e treinamento efetivos;

- Linhas de comunicação, incluindo um canal para recebimento de comunicações e denúncias anônimas acerca de violação de regras do programa;

- Auditorias e monitoramentos internos;

- Medidas disciplinares aplicáveis no caso de violação comprovada de regras de Compliance, que deverão ser amplamente divulgadas;

- $\quad$ Procedimentos de punição;

Como se pode ver, o Compliance, na área da saúde, envolve um comprometimento completo da empresa e acaba mudando de forma integral os mecanismos de gestão das empresas. Ele acaba por criar normas e regras éticas e de conduta, políticas, procedimentos e controles internos, que são capazes de garantir, que a empresa previna, em todos os seus âmbitos de atuação, a prática de ilícitos, em especial aqueles de corrupção. Nesse sentido, seria importante que essas medidas, hoje existentes apenas como mecanismo de autoregulação, fossem formalizadas por meio de uma legislação consistente, que torne obrigatória a exigência de um programa de Compliance para todas as pessoas jurídicas, que se envolverem direta ou indiretamente com a área da saúde. Somente assim 
se estará dando um passo concreto no enfrentamento sistemático das distorções no mercado de saúde no Brasil.

\section{CONSIDERAÇÕES FINAIS}

De todo o exposto, é possível extrair algumas conclusões, ainda que as mesmas devam ser submetidas ao crivo do contraditório (finalidade mesmo do presente artigo) e careçam de maior desenvolvimento e reflexão.

Uma primeira consideração pode ser feita no sentido de reconhecer que a assim chamada reserva do possível, nas suas diversas dimensões, pode operar, por um lado, como limite (jurídico e fático) ao direito à proteção e promoção da saúde, e, portanto, do controle judicial nessa seara, mas também como mecanismo de fortalecimento do sistema de saúde.

Além disso, é possível afirmar que o ferramental do Compliance permite, se bem manejado e assumido pelos atores estatais e privados, criar mecanismos de prevenção, resultando, justamente, no melhor desempenho do sistema de saúde, da racionalização dos recursos, da sua otimização e da sua sustentabilidade, resultando, provavelmente, na própria diminuição do recurso ao Poder Judiciário, ou, quando esta ocorrer, na redução do seu impacto.

É claro que se cuida também de um processo de conscientização, de uma "tomada de atitude", no sentido da criação e da introjeção de uma cultura do Compliance, seja como regulador de cunho ético, mas também com gradual projeção na esfera jurídica, processo que, embora alguns passos já dados, ainda está longe de se consolidar, mas cujos benefícios deverão ser significativos.

Ao fim e ao cabo, resta desde logo uma certeza: com Compliance o sistema de saúde será mais saudável e o direito à saúde mais efetivo!

\section{NOTAS}

10 presente capítulo foi em grande parte extraído da obra: SARLET, Ingo Wolfang. A Eficácia dos Direitos Fundamentais, 12 $2^{\underline{a}}$ ed., Porto Alegre: Livraria do Advogado, 2015.

2 Cf. C. Starck, in: BVerfG und GGII, p. 518. Assim também MURSWIEK, Dietrich. Grundrechte als Teilhaberechte, soziale Grundrechte. In: J. Isensee-P. Kirchhof (Org). Handbuch des Staatsrechts der Bundesrepublik Deutschland, V, p. 267, que, contudo, aponta para o fato de que as circunstâncias econômicas podem eventualmente vir a ser objeto necessário de consideração, 
especialmente nas hipóteses de restrições aos direitos de defesa, quando da aferição da proporcionalidade da restrição.

3 Assim, entre nós, LOPES, José Reinaldo de Lima. Direito Subjetivo e Direitos Sociais: o dilema do judiciário no Estado Social de Direito. In: Direitos Humanos, Direitos Sociais e Justiça. São Paulo: Malheiros, 1974. P. 131. No mesmo sentido, v. MENDES, Gilmar Ferreira. A Doutrina Constitucional e o Controle de Constitucionalidade como Garantia da Cidadania - Necessidade de Desenvolvimento de Novas Técnicas de Decisão: Possibilidade da Declaração de Inconstitucionalidade sem a Pronuncia de Nulidade no Direito Brasileiro. In: Caderno de Direito Tributário e Finanças Publicas no 3. 1993. P. 28, ressaltando que a efetividade dos direitos sociais se encontra na dependência da atual disponibilidade de recursos por parte do destinatário da pretensão. Também KRELL, Andreas. Controle judicial dos serviços públicos básicos na base dos direitos fundamentais sociais. In: SARLET, Ingo Wolfgang (Org.). A Constituição Concretizada - Construindo pontes para o público e o privado. Porto Alegre: Livraria do Advogado, 2000. P. 40 e ss., em importante ensaio sobre o tema, aceita esta dependência dos direitos sociais prestacionais da existência de recursos para sua efetivação, sem, contudo, negar-lhes eficácia e efetividade.

4 Esta, dentre outros, a lição de C. Starck, In: BverfG und GG II, p. 518.

5 A este respeito, v. também BRUNNER, Georg. Die Problematik der sozialen Grundrechte. In: Recht und Staar Nr. 404-405, J. C. B. Mohr (Paul Siebeck), Tubingen, 1971. P. 16. Entre nós, tal dimensão cresce em relevo se levarmos em conta o problema da repartição de competência no âmbito do Estado Federal e, acima de tudo, na repartição das receitas tributárias e sua afetação e aplicação, temática que aqui não há como desenvolver. Sobre o tema, enfatizando o direito à saúde, v. a contribuição de GOUVÊA, Marcos Maselli. $O$ direito ao fornecimento estatal de medicamentos. In: A Efetividade dos Direitos Sociais, 2004. P. 255 e ss..

6 Entre nós, v. MENDES, Gilmar Ferreira. A Doutrina Constitucional e o Controle de Constitucionalidade como Garantia da Cidadania - Necessidade de Desenvolvimento de Novas Técnicas de Decisão: Possibilidade da Declaração de Inconstitucionalidade sem a Pronuncia de Nulidade no Direito Brasileiro. In: Caderno de Direito Tributário e Finanças Publicas no 3. 1993. P. 28. Mais recentemente, $v$. as contribuições de TORRES, Ricardo Lobo. A cidadania multidimensional na Era dos Direitos. In: TORRES, Ricardo Lobo (Org.), Legitimação dos Direitos Humanos, Rio de Janeiro, Renovar, 1999. P. 292 e ss., assim como P. G. Gonet Branco. In: Hermenêutica constitucional e direitos fundamentais, p. 145 e ss. Na doutrina lusitana, posiciona-se favoravelmente ao reconhecimento do limite da reserva do possível ANDRADE, José Carlos Vieira de. Os Direitos Fundamentais na Constituição Portuguesa de 1976, Coimbra: Livraria Almedina, 1987. P. 201.

7 Vale anotar, que, embora a substancial convergência, há quem prefira atribuir um caráter dúplice (ou bidimensional) à assim designada "reserva do possível", como é o caso de SARMENTO, Daniel. A proteção judicial dos direitos sociais: alguns parâmetros ético-jurídicos. In: SOUZA NETO, Claudio Pereira. e SARMENTO, Daniel (Coord.), Direitos Sociais, Rio de Janeiro: Lumen Juris, 2008. P. 569 e ss., embora sem deixar, mas não no contexto específico das "dimensões" da reserva do possível, de referir a necessária observância dos critérios da proporcionalidade, designadamente, como sempre fizemos questão de enfatizar, abrangendo a razoabilidade da pretensão do particular em face do Estado e da comunidade. No mesmo sentido, v., ainda, CALIENDO, Paulo. Direito Tributário e Análise Econômica do Direito. Uma visão crítica. São Paulo: Elsevier, 2008. P. 204, reconhecendo uma dimensão fática e jurídica da reserva do possível. De qualquer sorte, o mais importante é que se tenha presente que a problemática posta pela reserva do possível abrange um conjunto diferenciado de aspectos, que não pode ser reduzido à questão da efetiva disponibilidade de recursos materiais. Enfatizando também o caráter multidimensional da reserva do possível, v., por último, KELBERT, Fabiana Okchstein. Reserva do Possível e a Efetividade dos Direito sociais no Direito Brasileiro, Porto Alegre: Livraria do Advogado, 2011. P. 65.

8 Reunindo um conjunto de ensaios sobre as diversas perspectivas da "reserva do possível", inclusive veiculando posições mais ou menos divergentes entre si, no sentido de um autêntico debate sobre o tema, v., por último, SARLET, Ingo Wolfang. Timm (Orgs.), Direitos Fundamentais, Orçamento e "Reserva do Possível". Porto Alegre: Livraria do Advogado, 2008.

9 Neste sentido, pelo menos, a recente afirmação de SCHÄFER, Jairo. Classificação dos Direitos Fundamentais: do Sistema Geracional ao Sistema Unitário - uma proposta de compreensão, Porto 
Alegre: Livraria do Advogado, 2005. P. 67. Nas palavras do autor, a reserva do possível "é um elemento que se integra a todos os direitos fundamentais". Em verdade, o próprio autor - na esteira da doutrina precedente - reconhece na reserva do possível uma condicionante jurídica ou concreta à efetivação dos direitos, de tal sorte que, a despeito da contradição, resulta claro que o autor vislumbra na reserva do possível um limite fático e jurídico que incide, em princípio, em relação a todos os direitos fundamentais.

10 o presente capítulo é, em grande medida, uma versão revisada e adaptada para o presente artigo do parecer que Giovani Agostini Saavedra apresentou, como especialista convidado, na CPI da Máfia das Próteses realizada pela Assembleia do Estado do Rio Grande do Sul.

11 Sobre as mudanças da nova lei, ver: SAAVEDRA, Giovani Agostini. Compliance na Nova Lei de Lavagem de Dinheiro. In: Revista Síntese - Direito Penal e Processual Penal, Ano XIII, no. 75, Ago-Set, 2012, P. 22-30 e SAAVEDRA, Giovani Agostini. Compliance e Prevenção à Lavagem de Dinheiro: sobre os reflexos da Lei no. 12.683/2012 no Mercado de Seguros. In: Revista de Estudos Criminais, n‥ 54. Jul./Set, 2014, P. 165-180.

12 Ver, a esse respeito: ABBI - Associação Brasileira dos Bancos Internacionais; FEBRABAN - Federação Brasileira de Bancos, Cartilha Função de Compliance, Agosto 2003 com atualização em Julho de 2009 (Disponível: www.febraban.com.br); COIMBRA; Marcelo de Aguiar; MANZI, Vanessa Alessi Manual de Compliance. Preservando a Boa Governança e a Integridade das Organizações, São Paulo: Atlas, 2010. P. 12 e ss.; MANZI, Vanessa Alessi. Compliance no Brasil. Consolidação e perspectivas, São Paulo: Saint Paul, 2008. P. 64 e ss.; ANDRADE, Adriana; ROSSETTI, José Paschoal. Governança Corporativa. Fundamentos, Desenvolvimento e Tendências. São Paulo: Atlas, 2009. P. 183 e ss..

13 A decisão referida é a BGH Entscheidung von 17.07.2009-5 StR 394/08.

140 conceito de paradoxo é empregado aqui no sentido dado por: HARTMANN, Martin; HONNETH, Axel. Paradoxien des Kapitalismus. Ein Untersuchungsprogram. In: Berliner Debatte Initial 15 (2004) 1, S. 9.

15 Para um panorama sobre a discussão sobre Compliance na Alemanha, ver: ROTSCH, Thomas. Criminal Compliance. In: Zeitschrift für Internationale Strafrechtsdogmatik. Ausgabe 10/2010, 5. Jahrgang, P. 614 e ss.; HAUSCHKA, Christoph E. Corporate Compliance. Handbuch der Haftungsvermeidung im Unternehmen. München: C.H. Beck, 2010; GÖRLING, Herlmut; INDERST, Cornelia; BANNENBERG, Britta. Compliance. Aufbau - Managment - Risikobereiche, München: C.H. Beck, 2010.

16 Essa é a crítica e a sugestão de BARBOSA, DANIEL MARCHIONATTI, Ferramentas Velhas, novos problemas: deficiências da utilização da lei dos crimes contra o sistema financeiro para coibir descumprimento de deveres de compliance. In: T. HIROSE; J. P. BALTAZAR JÚNIOR (Orgs.). Curso Modular de Direito Penal. Florianópolis: Conceito Editorial-EMAGIS, 2010, v. 2, p. 489-510.

17 Essa é a posição, por exemplo, de LIMA, Carlos Fernando. O Sistema Estadual Antilavagem de Dinheiro: as obrigações de Compliance. In: CARLI, Carla Veríssimo de. Lavagem de Dinheiro. Prevenção e Controle Penal. Porto Alegre: Verbo Jurídico, 2011, P. 84

18 Há também julgados que já começam a discutir a possibilidade de se exigir deveres de Compliance de contadores e advogados. Ver, por exemplo: "EMENTA: PENAL. EMBARGOS INFRINGENTES. LAVAGEM DE DINHEIRO. RESPONSABILIDADE PENAL DO ADVOGADO E DO CONTADOR. INEXISTÊNCIA DE DEVER DE COLABORAÇÃO. AUSÊNCIA DE CIRCUNSTÂNCIAS FACTUAIS OBJETIVAS. ABSOLVIÇÃO. RECURSO PROVIDO. 1. Os artigos 9o e 10 da Lei 9.613/98 não incluem o contador e o advogado entre os profissionais que possuem dever de colaboração (compliance) com a repressão à lavagem de dinheiro (identificação de clientes, manutenção de registros e comunicação de operações financeiras com sérios indícios de lavagem de dinheiro). 2. 0 próprio Conselho Estadual de Contabilidade não exige do contador a obrigação de fiscalizar a veracidade das informações que lhe são repassadas pelos seus clientes, conforme muito bem observou o ilustre Juiz Estadual Eduardo Gomes Philippsen na sentença proferida na AP nº 2007.71.04.004606-0/ RS. Evidentemente, isso não significa que um profissional da contabilidade jamais poderá ser responsabilizado criminalmente. Por ocasião do julgamento da ACR no 2004.04.01.025529-6, Rel. Juíza Estadual ELOY BERNST JUSTO, D.E. 28-06-2007, a Oitava Turma da Corte teve a oportunidade de manter a condenação por sonegação fiscal de um contador que trabalhava em um departamento de contabilidade exclusivo da aludida escola de informática, o qual controlava diretamente todas as falsidades fiscais que propiciaram vultoso crime contra a ordem tributária. 
3. Ademais, a simples prestação de serviços advocatícios pelo acusado (contador e advogado) por ocasião da constituição da empresa utilizada para a ocultação de capital proveniente de tráfico interEstadual de drogas não é, por si só, suficiente para justificar a sua condenação, porque a acusação não logrou êxito em indicar na denúncia e comprovar ao longo da instrução que o réu teria incorrido no tipo penal do artigo $1^{\circ}$, inciso I, $\S 2^{\circ}$, I e II da Lei $9.613 / 98$, isto é, que sabia dos propósitos obscuros da aludida pessoa jurídica. 4. Portanto, se é verdade que advogados e contadores também podem praticar o branqueamento de capitais quando as circunstâncias factuais objetivas preconizadas pelo artigo 6º, item 2, "f", da Convenção das Nações Unidas contra o Crime Organizado TransEstadual (v.g. pagamento de honorários em espécie, valores fracionados, em joias) demonstrarem que houve subversão da sua atuação profissional, orientando e auxiliando, direta ou indiretamente, seus clientes no desiderato de ocultar ou dissimular valores provenientes dos delitos precedentes, também é certo que esses profissionais liberais não podem ser incriminados pelo simples contato que tiverem com os autores dos crimes antecedentes quando o órgão acusatório deixar de demonstrar, com segurança, como no caso em tela, os aspectos que denotam a ciência dos fins ilícitos da assessoria prestada. 5. Embargos infringentes providos." BRASIL. Tribunal Regional Federal da 4a Região. ENUL - Embargos Infringentes e de Nulidade $n^{\circ}$ 2007.70.00.026565-0. Embargante: Humberto Marcelino Ferreira. Relator Paulo Afonso Brum Vaz, Porto Alegre, RS, D.E. 24 jun. 2011. Porém, os julgados que existem acerca do tema são todos anteriores à nova resolução do Conselho Estadual de Contabilidade, que regula os deveres de Compliance da classe. Portanto, fica a dúvida se as decisões teriam sido diferentes, se os julgadores tivessem à sua disposição essa resolução.

19 SAAVEDRA, Giovani Agostini, Reflexões Iniciais sobre Criminal Compliance, in: Boletim IBCCRIM. São Paulo: IBCCRIM, ano 18, n. 218, p. 11-12, jan./2011; SILVEIRA, Renato de Mello Jorge; SAAD-DINIZ, Eduardo. Criminal Compliance: os limites da cooperação normativa quanto à lavagem de dinheiro. In: Revista de Direito Bancário e Mercado de Capitais. Vol. 56. Abril. São Paulo: RT, 2012. COSTA, Helena Regina Loba da; ARAUJO, Marina Pinhão Coelho. Compliance e o Julgamento da APn 470. In: Revista Brasileira de Ciências Criminais, Ano 22, no. 106, Jan-Fev/2014. P. 215-230.

\section{REFERÊNCIAS}

ABBI - Associação Brasileira dos Bancos Internacionais; FEBRABAN - Federação Brasileira de Bancos. Cartilha Função de Compliance. Agosto 2003 com atualização em Julho de 2009. Disponível em: <www.febraban.com.br>.

ADVAMED. Código de Ética da Advamed. 2009. p. 1-2. Disponível em: < http:// advamed.org/issues/1/code-of-ethics>. Acesso em: 22 jan. 2016.

AMARAL, Gustavo. Direito, escassez e escolha. Rio de Janeiro: Renovar, 2001.

ANDRADE, José Carlos Vieira de. Os direitos fundamentais na constituição portuguesa de 1976. Coimbra: Livraria Almedina, 1987.

ANDRADE, Adriana; ROSSETTI, José Paschoal. Governança Corporativa: fundamentos, desenvolvimento e tendências. São Paulo: Atlas, 2009.

BGH Entscheidung von 17.07.2009-5 StR 394/08. 
BRANCO, Paulo Gustavo Gonet. Aspecto de Teoria Geral de Direitos Fundamentais. In: MENDES, Gilmar Ferreira; COELHO, Inocêncio Mártires; BRANCO, Paulo Gustavo Gonet. Hermenêutica constitucional e direitos fundamentais. Brasília: Brasília Jurídica, 2000.

BRASIL. Tribunal Regional Federal da 4⿳亠丷厂 Região. Apelação Criminal no 5008326 03.2010.404.7100. Apelante: Ministério Público Federal. Apelado: Carlos Fernando de Conto. Relator Paulo Afonso Brum Vaz, Porto Alegre, RS, 22 nov. 2010. Processo Eletrônico. Disponível em: < http://jurisprudencia.trf4.jus.br/ pesquisa/inteiro_teor.php?orgao $=1 \&$ documento $=3715061>$. Acessado em: 27 out. 2016.

BRASIL. Tribunal Regional Federal da 4⿳亠丷厂 Região. ENUL - Embargos Infringentes e de Nulidade no 2007.70.00.026565-0. Embargante: Humberto Marcelino Ferreira. Relator Paulo Afonso Brum Vaz, Porto Alegre, RS, D.E. 24 jun. 2011.

BARBOSA, Daniel Marchionatti. Ferramentas Velhas, Novos Problemas: deficiências da utilização da lei dos crimes contra o sistema financeiro para coibir descumprimento de deveres de compliance. In: HIROSE, T.; BALTAZAR JÚNIOR, J. P. (Org.). Curso modular de direito penal. Florianópolis: Conceito EditorialEMAGIS, 2010. v. 2.

BRUNNER, Georg. Die Problematik der sozialen Grundrechte. In: Recht und Staar Nr. 404-405, J. C. B. Mohr (Paul Siebeck), Tubingen, 1971.

GALDINO, Flávio. O custo dos direitos. In: Torres, R. L. (Org). Legitimação dos direitos humanos. Rio de Janeiro: Renovar, 2002.

CALIENDO, Paulo. Direito tributário e análise econômica do direito: uma visão crítica. São Paulo: Elsevier, 2008.

CAMPOS, Marcelo da Silveira Campos. Crime e Congresso Nacional: uma análise da política criminal aprovada de 1989 a 2006. São Paulo: IBCCRIM, 2010.

CANOTILHO, Joaquim José Gomes. Constituição dirigente e vinculação do legislador. Coimbra: Coimbra Editora, 1982.

COIMBRA; Marcelo de Aguiar; MANZI, Vanessa Alessi. Manual de compliance: preservando a boa governança e a integridade das organizações. São Paulo: Atlas, 2010. 
COSTA, Helena Regina Loba da; ARAUJO, Marina Pinhão Coelho. Compliance e o julgamento da APn 470. Revista Brasileira de Ciências Criminais, São Paulo, n, 106, p. 215-230, jan./fev., 2014.

ÉTICA SAÚDE. Guia de implementação. Disponível em: <http://www.eticasaude.com.br/implementacao.html>. Acesso em: 22 jan. 2016.

GOUVÊA, Marcos Maselli. O controle judicial das omissões administrativas: novas perspectivas de implementação dos direitos prestacionais. Rio de Janeiro: Forense, 2003.

GOUVÊA, Marcos Maselli. O direito ao fornecimento estatal de medicamentos. In: GARCIA, Emerson (Coord.). A efetividade dos direitos sociais. Rio de Janeiro: Lumen Juris, 2004.

GÖRLING, Herlmut; INDERST, Cornelia; BANNENBERG, Britta. Compliance. Aufbau - Managment - Risikobereiche. München: C.H. Beck, 2010.

GRUNDLAGE,Thomas Rotsch. In: Rotsch, Thomas (Org.). Criminal compliance handbuch. Baden-Baden: Nomos, 2015.

HARTMANN, Martin; HONNETH, Axel. Paradoxien des Kapitalismus. Ein Untersuchungsprogram. In: Berliner Debatte Initial 15 (2004) 1, S. 9.

HAUSCHKA, Christoph E. Corporate Compliance. Handbuch der Haftungsvermeidung im Unternehmen. München: C.H. Beck, 2010;

KELBERT, Fabiana Okchstein. Reserva do Possível e a Efetividade dos Direito Sociais no Direito Brasileiro. Porto Alegre: Livraria do Advogado, 2011.

KRELL, Andreas. Controle Judicial dos Serviços Públicos Básicos na Base dos Direitos Fundamentais Sociais. In: SARLET, Ingo Wolfgang (Org.). A Constituição concretizada: construindo pontes para o público e o privado. Porto Alegre: Livraria do Advogado, 2000.

LEITE, Alaor. Domínio do fato, domínio da organização e responsabilidade penal por fatos de terceiros sobre os conceitos de autor e partícipe na APn 470 do STF. Revista Brasileira de Ciências Criminais, São Paulo, n. 106, p.47-90,jan./fev., 2014.

LIMA, Carlos Fernando. 0 sistema estadual antilavagem de dinheiro: as obrigações de compliance. In: CARLI, Carla Veríssimo de. Lavagem de dinheiro: prevenção e controle penal. Porto Alegre: Verbo Jurídico, 2011. 
LOPES, José Reinaldo de Lima. Direito subjetivo e direitos sociais: o dilema do judiciário no Estado Social de Direito. In: FARIA, José Eduardo (Org.). Direitos humanos, direitos sociais e justiça. São Paulo: Malheiros, 1974.

NABAIS, José Casalta. Por uma liberdade com responsabilidade: estudos sobre direitos e deveres fundamentais. Coimbra: Coimbra Editora, 2007.

MANZI, Vanessa Alessi. Compliance no Brasil: consolidação e perspectivas. São Paulo: Saint Paul, 2008.

MENDES, Gilmar Ferreira. A doutrina constitucional e o controle de constitucionalidade como garantia da cidadania: necessidade de desenvolvimento de novas técnicas de decisão: possibilidade da declaração de inconstitucionalidade sem a pronuncia de nulidade no direito brasileiro. Cadernos de Direito Tributário e Finanças Públicas, São Paulo, n. 3, p. 21-43, abr./jun., 1993.

MURSWIEK, Dietrich Grundrechte als Teilhaberechte, soziale Grundrechte. In: J. Isensee-P. Kirchhof (Org). Handbuch des Staatsrechts der Bundesrepublik Deutschland, V.

OLSEN, Ana Carolina Lopes. Direitos fundamentais sociais: efetividade frente a reserva do possível. Curitiba: Juruá, 2008.

ROTSCH, Thomas. Criminal Compliance. In: Zeitschrift für Internationale Strafrechtsdogmatik. Ausgabe 10/2010, 5. Jahrgang.

ROTSCH, Thomas. Recht - Wirtschaft - Strafe. Festschrift für Erik Samson zum 70. Geburstag. München: C.H. Beck, 2010.

SARLET, Ingo Wolfang. A eficácia dos direitos fundamentais. 12. ed. Porto Alegre: Livraria do Advogado, 2015.

SARLET, Ingo Wolfang. TIMM, Luciano Benetti (Org.). Direitos fundamentais, orçamento e "reserva do possível". Porto Alegre: Livraria do Advogado, 2008.

SARMENTO, Daniel. A proteção judicial dos direitos sociais: alguns parâmetros ético-jurídicos. In: SOUZA NETO, Claudio Pereira; SARMENTO, Daniel (Coord.). Direitos Sociais. Rio de Janeiro: Lumen Juris, 2008.

SAAVEDRA, Giovani Agostini. Compliance e prevenção à lavagem de dinheiro: sobre os reflexos da Lei no. 12.683/2012 no mercado de seguros. Revista de Estudos Criminais, n. 54. Jul./set., 2014. 
SAAVEDRA, Giovani Agostini. Compliance na nova lei de lavagem de dinheiro. Revista Síntese - Direito Penal e Processual Penal, Ano XIII, n 75, ago./set, 2012.

SAAVEDRA, Giovani Agostini. Reflexões iniciais sobre criminal compliance. Boletim IBCCRIM, São Paulo, ano 18, n. 218, jan., 2011.

SCHÄFER, Jairo. Classificação dos Direitos Fundamentais: do sistema geracional ao sistema unitário: uma proposta de compreensão. Porto Alegre: Livraria do Advogado, 2005.

SGARBOSSA, Luiz Fernando. Crítica à teoria dos custos dos direitos: reserva do possível. Porto Alegre: Sergio Antônio Fabris, 2010. vol. I.

SILVA, Virgílio Afonso da. 0 judiciário e as políticas públicas: entre transformação social e obstáculo à realização dos direitos sociais. In: SOUZA NETO, Claudio Pereira; SARMENTO, Daniel (Coord.). Direitos Sociais. Rio de Janeiro: Lumen Juris, 2008.

SILVEIRA, Renato de Mello Jorge; SAAD-DINIZ, Eduardo. Criminal compliance: os limites da cooperação normativa quanto à lavagem de dinheiro. Revista de Direito Bancário e Mercado de Capitais, São Paulo, v. 56, abril, 2012.

TORRES, Ricardo Lobo. A cidadania multidimensional na era dos direitos. In: TORRES, Ricardo Lobo (Org.). Legitimação dos direitos humanos. Rio de Janeiro: Renovar, 1999.

WIPFELDER, Hans-Jurgen. Die verfassungsrechtliche Kodifizierung sozialer Grundrechte. In: ZRP 1986.

Recebido em: 27-10-2016

Aprovado em: 01-6-2017 


\section{Ingo Wolgang Sarlet}

Doutor em Direito pela Ludwig-Maximillians-Universität München (1997). Realizou estudos de Pós-Doutorado, como Bolsista e Pesquisador do Instituto Max-Planck de Direito Social, Estrangeiro e Internacional (Alemanha), bem como no Georgetown Law Center (Washington DC, 2004), assim como na Universidade de Munique (supervisão de Claus-Wilhelm Canaris) como bolsista do DAAD (2005). Coordenador do Programa de Pós-Graduação em Direito PUC-RS. Professor Titular da Faculdade de Direito e dos Programas de Mestrado e Doutorado em Direito e em Ciências Criminais da Pontifícia Universidade Católica do Rio Grande do Sul (PUCRS). Coordenador do Grupo de Estudos e Pesquisas em Direitos Fundamentais - CNPq. Desembargador do TJRS. E-mail: iwsarlet@gmail.com

Pontifícia Universidade Católica do Rio Grande do Sul, Pós-Graduação em Direito - Mestrado e Doutorado.

Av. Ipiranga, 6681 PUC-RS. Partenon. CEP 90619900 - Porto Alegre, RS - Brasil - Caixa-postal: 1429

\section{Giovani Agostini Saavedra}

Doutor em Direito e em Filosofia pela Johann Wolfgang Goethe - Universität Frankfurt am Main (Alemanha). Mestre em direito e graduado em Ciências Jurídicas e Sociais pela PUCRS. Professor de Direito Penal, Compliance e Filosofia do Direito na Faculdade de Direito PUC-RS, professor e coordenador da Especialização em Compliance da PUCRS, professor dos Programas de Pós-Graduação em Ciências Criminais e em Direito da PUCRS (Mestrado e Doutorado). Secretário-Geral do Instituto Transdisciplinar de Estudos Criminais (ITEC), Coordenador do Núcleo de Pesquisa em Compliance, Governança Corporativa \& Inovação e Coordenador da Comissão Científica da Faculdade de Direito da PUC-RS. E-mail: saavedra@srgadvogados.com

Pontifícia Universidade Católica, Programa de Pós-Graduação em Ciências Criminais.

Av. Ipiranga, 6681 (Prédio 11, 10o. Andar). Partenon. CEP 90619-900 - Porto Alegre, RS - Brasil 